\title{
Multi-Method END Study in the Search for 'Defects' in an Aeronautical Radar Element
}

\author{
Gaston Sanglier ${ }^{1}$, Jose Miguel $^{2}$, Jose Antonio Penaranda ${ }^{2} \&$ y Gabriel Del Ojo ${ }^{2}$ \\ ${ }^{1}$ Central Laboratory of Remote Sensing. Instituto Nacional de Técnica Aeroespacial (INTA), Crta. Ajálvir Km.4, \\ 28850 Torrejón de Ardoz, Madrid, Spain \\ ${ }^{2}$ Non-Destructive Testing Laboratory. Instituto Nacional de Técnica Aeroespacial (INTA), Crta. Ajálvir Km.4, \\ 28850 Torrejón de Ardoz, Madrid, Spain \\ Correspondence: Gaston Sanglier, Instituto Nacional de Técnica Aeroespacial (INTA), Crta. Ajálvir Km.4, \\ 28850 Torrejón de Ardoz, Madrid, Spain.
}

Received: September 18, 2020

doi:10.5539/mas.v14n11p19
Accepted: October 26, 2020

Online Published: October 27, 2020

URL: https://doi.org/10.5539/mas.v14n11p19

\begin{abstract}
Non-Destructive Testing (NDT) has gone from being a simple laboratory curiosity to an indispensable tool in the industry to determine the level of quality achieved in its products. The new concepts of Integrated Manufacturing (CIM) bring a more universal concept of quality compared to the past philosophy based on Quality Control as a group specialized in checking whether production works within certain specifications. Even so, NDTs have not lost interest, but have seen their interest increased due to automated inspection techniques. It has become a contribution to the structuring of quality as it allows to move from purely empirical criteria to other more objective and that constitute the link between design and evaluation (Ramirez et al, 1996).

The work presented, although it does not propose new methods or techniques of NDT, has the interest of converging into a single object five conventional methods each of which provides partial information about their quality of manufacture and must synthesize the results in order to evaluate it. Furthermore, it shows a situation of the application of NDT in which these must be applied in the absence of reference standards, as they do not exist. This peculiar situation is completely different from the usual situation in the use of NDT in the industry, both in manufacturing processes and in maintenance inspections.
\end{abstract}

Keywords: non-destructive testing, ultrasound, thermography, radiography, acoustic, ultraviolet, visual

\section{Introduction}

In the scientific tradition, observation plays a major role. When the observed phenomenon has been provoked, you have the experiment. Through the experiment, the behavior of Nature is verified under controlled conditions in order to discover regularities that can be described in a logical way and be enunciated as laws. In technology, it is not so much important to discover natural laws as to apply them to questions of immediate utility, and so the experiment shortens its scope and becomes an experiment, in such a way that it can be indicated that an experiment is a technological experiment (Sanglier et al., 2020).

According to the testing of materials, they can be divided into three categories:

- Functional tests

- Destructive Testing

- Non-Destructive Testing

This work will refer to the Non-Destructive Tests that should be adapted to the requirements of the sample to avoid its deterioration. This is achieved by resorting to those physical characteristics of the material that are technologically significant, and as these can be very varied (density, thermal conductivity, electromagnetic absorbance, refractive index, crystalline structure, etc.) hence the number of Non-Destructive Tests is potentially large and their basis diverse.

From the point of view of their fundamentals, Non-Destructive Tests are mainly based on the application of one or several of the following physical phenomena 
- Electromagnetic waves, including phenomena based on the electrical and/or magnetic properties of the samples

- Elastic or acoustic waves

- Subatomic particle emission

- Other phenomena such as capillarity, watertightness, absorption, etc.

In terms of applications, Non-Destructive Testing methods cover three broad areas:

- Defectology: detection of heterogeneities, discontinuities and impurities; evaluation of corrosion and deterioration by environmental agents; determination of stresses; detection of leaks; defects in moving machinery; hot spots.

- Material characteristics: chemical, structural, mechanical and technological characteristics; physical (elastic, electrical and electromagnetic); heat transfer and isothermal trace.

- Metrology: thickness control; one-sided thickness measurement; coating thickness measurement; filling levels.

The problem that appears with the application of the different NDT techniques is that it is not very well known since it depends on many factors, which will be the most suitable technique for each type of inspection. For example, in non-destructive testing without contact and in the astronautical field, very high demands are made. The materials used in this very specialized branch of engineering must not only have very high quality levels, but also the tests that require their verification must be such that they do not produce any type of contamination. This severe requirement eliminates many traditional techniques and even some methods. This is the case, for example, with penetrating liquids, magnetic particles or contact ultrasound. In fact, only visual inspection or radiography meets these requirements and, under certain operating conditions, currents induced by mentioning traditional methods. Stimulated by this need, some methods have developed very sophisticated specific techniques that allow physical contact to be replaced by optical contact (surface holography, holographic interferometry, infrared thermography). For example, it is possible to stimulate the generation of ultrasounds in a material by means of laser 'impact' and 'read' by this same means the fine vibrations generated.

The main interest of this work is that it is a rare example of the application in a single object (piece) of a considerable number of non-destructive tests. Nor is't common that this is done in the absence of specifications, both the procedure for conducting the tests and acceptance-rejection criteria (ASM, 1989; Barbero, 1999). This is unusual in the industrial field where the rule is to follow an operating procedure specification, specially prepared for each specific case, based on solvent standards and containing clear and unequivocal acceptance-rejection criteria.

On the other hand, most often the tests to be performed on each specimen are not numerous for well-defined products. Two or three is normal; sometimes just one. And in any case related, if not in their physical basis, then in their purpose of trying to highlight certain well-determined types of discontinuities and not others (Baker, Jones \& Callinan, 1985; Bishop, 1985).

However, when it comes to establishing the degree of confidence that we deserve in the behavior in service of a newly designed object, made perhaps of a rare material of which there are few examples, perhaps only one, and which is also going to serve an application of which there is no direct previous experience, it is clear that the doctrine commonly followed in the industry is not useful (Heru et al., 1997; Scarponi \& Briotti, 2000; Miyano et al., 1994).

In these cases, not uncommon in applied research, the only possible guide is a judicious theoretical analysis of the service conditions and the behavior of the material under those conditions and according to a concrete design. The result is a theoretical "model", if you want "virtual", which only has the value of being a reasonable basis for approaching the real behavior of the object (Huang et al., 1998; Kapranos \& Priestner, 1987). As this is insufficient, it will be necessary to make representative samples with controlled discontinuities and even better, a prototype to test it under conditions qualitatively similar to those of service and quantitatively more severe, being advisable to prolong the tests until the failure occurs. Only from the experience gathered in such tests and from the previous theoretical analyses is it possible to extract the essential information to draw up quality specifications and to establish reliable acceptance-rejection criteria.

\section{Methods}

For some time now, INTA has been developing a radar system for stereometric surveying of the relief of large areas of land. As the resolution is given by the opening of the system and this depends on the size of the antenna, to achieve high resolutions would be necessary very large antennas. As, on the other hand, the surveys are 
intended to be performed from an aircraft in flight, such antennas would be virtually impossible to mount on board. These drawbacks can be avoided by what is known as "synthetic aperture" which consists of making distant shots during flight that meet certain phase matching conditions, so that the system behaves as if it had an aperture equivalent to the distance between the shots. This is "grosso modo", the synthetic aperture radar developed by INTA (Sanglier et al., 2003; Balageas, 2005).

To carry out the functional tests of this system, a protective cover or "radome" has been developed, transparent to electromagnetic waves in the order of frequencies used, which replaces one of the doors of the test plane, behind which the radar is located.

Since the "radome", or "radar dome", must be subjected to mechanical stresses due to vibrations and aerodynamic pressures, and its failure could have serious consequences, it is necessary through various tests, including non-destructive ones, to estimate whether its quality is sufficient to guarantee that it will not fail. As only three specially designed pieces have been manufactured, it is obvious that no existing specifications or standards applicable to this type of object can be referred to.

The material of the radome, shown in figure 1, consists of a central sandwich structure and two monolithic side panels. The sandwich is manufactured from a $5 \mathrm{~mm}$ thick rigid organic foam core (rohacell 31 ) glued to two "skins", each consisting of two layers of fiberglass fabric (G 380T2/1990S) and resin giving a total thickness after curing of $0.4 \mathrm{~mm}$. Each side panel is $1.6 \mathrm{~mm}$ thick resulting from stacking eight layers of resin-impregnated fiberglass fabric. Eventually, it can be painted with an organic lacquer transparent to electromagnetic radiation. Although the shape of the piece is relatively simple, the formation of the strongest curvatures has forced cuts and joints that affect the continuity of the whole. This, on the other hand, has an aluminum alloy frame with the necessary holes to fix it to the door frame of the aircraft it replaces.

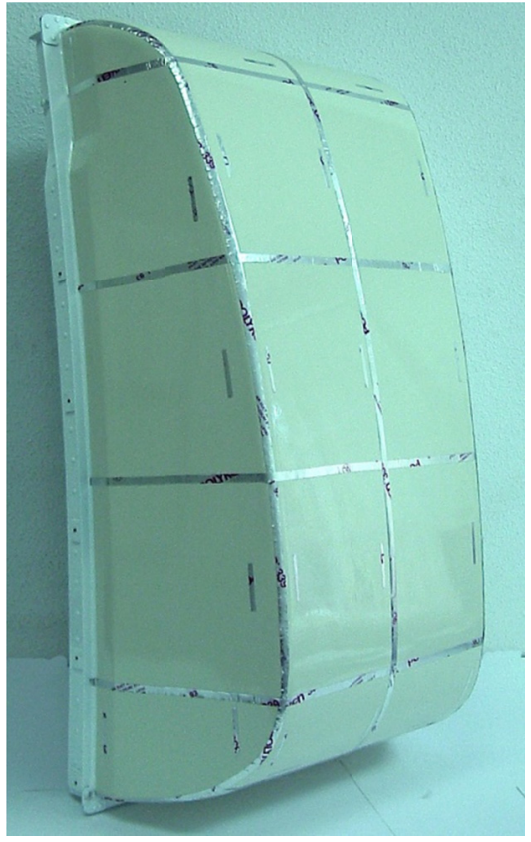

Figure 1. General view of the piece under study: Radomo

\subsection{Tests}

Non-destructive tests applied to the radome are not intended to verify dimensions or characterize the materials, but exclusively to highlight the presence of possible discontinuities that could affect its behavior in service. As such discontinuities are not well characterized and can be very varied (delaminations and detachments, cavities, inclusions of foreign materials, etc.) and affect both the core and the "skins", it's advisable to resort to as many methods as possible, according to the appropriate application techniques (Barbero, 1999; Gray et al., 1995; ImieliÈska et al., 2004, Ochelski, 2004; Padmanabhan \& Kishore, 1995; Maldague, 2001; Krapez, Taillade \& Balageas, 2003; David \& Hsu, 2006). The collection of such information should be contrasted with destructive tests in test tubes made according to the manufacturing criteria, and valued according to the design calculation estimates, which will not be analyzed in this work. Naturally, the methods used may be "complementary" when they report discontinuities of different nature, completing each other's results, or "concurrent" if two or more 
tests report the existence of the same discontinuity (Potel et al., 1998; Clauser, 1952; Rosethal \& Trolinger, 1995; Globe, 1979; Bales \& Bishop, 1994; David, Hsu, Barnard \& Daniel, 2004).

The applied essays (the basis of which is given as known) are the following:

- Visual.

- Radiographic.

- Ultrasound.

- Sonic.

- Thermography.

- Ultraviolet.

Penetrating liquids and in general any technique that involves contaminating the material with a coupling fluid were discarded (Wan et al., 2016; Silk, 1982).

The results achieved are described below, with emphasis on a comparison of those provided by one or another method.

\subsection{Operating Conditions}

Although depending on the method applied and the area of the parts where the specific operating conditions are applied, as a guideline we summarize below those that can be considered typical:

- Visual: Light levels between 500 and 1000 lux. Observation with the naked eye or with low power magnifiers $(<10 \mathrm{~d})$.

- Radiographic: X-rays from 40 to $45 \mathrm{KV}$. Exposures of 7 to $8 \mathrm{~mA}$ x min. without filters. Type I film without ASTM. Without reinforcement sheets. Focus-film distance irrelevant (900 $\mathrm{mm}$ was used). Focus of $0,8 \times 0,8 \mathrm{~mm}$.

- Ultrasound: Transmission by total immersion. Frequency: $1 \mathrm{MHz}$.

- Sonic: Scanning with continuous Lamb wave between 2.5 and $70 \mathrm{KHz}$.

- Thermography: Spectral range from 7.5 to $13 \mu \mathrm{m}$. FOV: $24^{\circ}$.

- Ultraviolet A: Wave length: $366 \mathrm{~nm}$. Energetic illumination: $10 \mathrm{w} / \mathrm{m}^{2}$.

\subsection{Discontinuities}

Given the nature of the material, the usual designation of discontinuities may have a different meaning than the common one in NDT, which normally comes from those found in metallic materials. Therefore, an attempt will be made to introduce descriptive names for most discontinuities (Mouritz, Townsend \& Shah Khan, 2000; Mitrevski, Marshall \& Thomson, 2006; Hasiotis, Badoggiannis \& Tsouvalis, 2007).

On the other hand, the visual definition of certain discontinuities is affected by the translucent nature of the material which can make its appearance diffuse. Finally, it's necessary to note the difficulty of graphic reproduction of a good part of the images obtained, so that those included in this work give a very poor idea of the originals (Lawson \& Sabey, 1970).

\section{Results}

\subsection{Test Pieces}

In order to test the effectiveness of different methods in detecting flat discontinuities, a master specimen was used in which different artificial discontinuities were introduced, such as peel-offs between "skin" and core on both sides of the specimen and core breaks in the central plane of the specimen.

First, the specimen was inspected with ultrasound transmission in total immersion. The image shown in figure 2 was obtained, where it can be seen that all the discontinuities (dark areas) existing in the upper and lower bands of the test tube have been detected, as well as other discontinuities, located in the central band of the test tube, which were not suspected. In the image you can see four holes (light circles) located in the corners, around which there are also areas with detachments. 


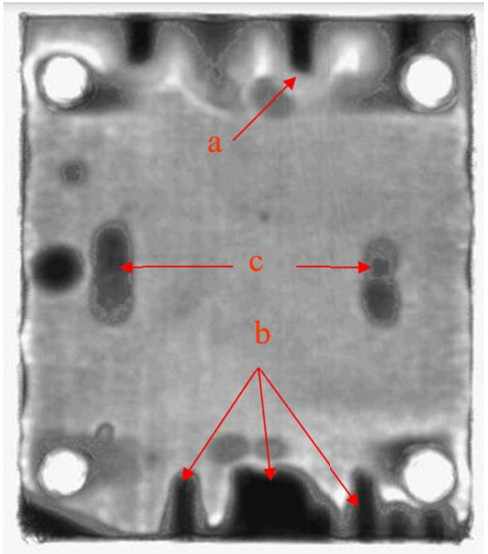

Figure 2. Image of a specimen with discontinuities obtained by transmission ultrasonic inspection

Using the transmission thermography technique (Sanglier et al., 2020; Cielo et al., 1987), the images in figure 3 were obtained, which correspond to the upper (left image) and lower (right image) bands of the pattern. From the examination of the left image, it can be seen that only a light color indication is visible at the top, just to the right of the center line (arrow a). This indication corresponds to a peeling off at the junction "skin"-core and appears as a dark rectangular area (arrow a) on the ultrasonic image (figure 2). In the lower band of the pattern, the agreement between ultrasonic and thermographic methods is greater, as can be seen by comparing the lower areas (arrows b) of the images represented in figure 2 and on the right side of figure 3 . On the other hand, the ultrasonic test provided a series of indications due to discontinuities in the central band of the pattern (arrows c) that could not be obtained by thermography.

As we have just seen, thermography is not very effective in detecting flat discontinuities in this material, the reason being the low contrast of the discontinuities obtained in thermographic images, the high power of thermal insulation of the core, which means that heat transmission is hardly affected by the existence of the take-offs, since the capacity to transmit heat is very similar in the core and in the take-off.
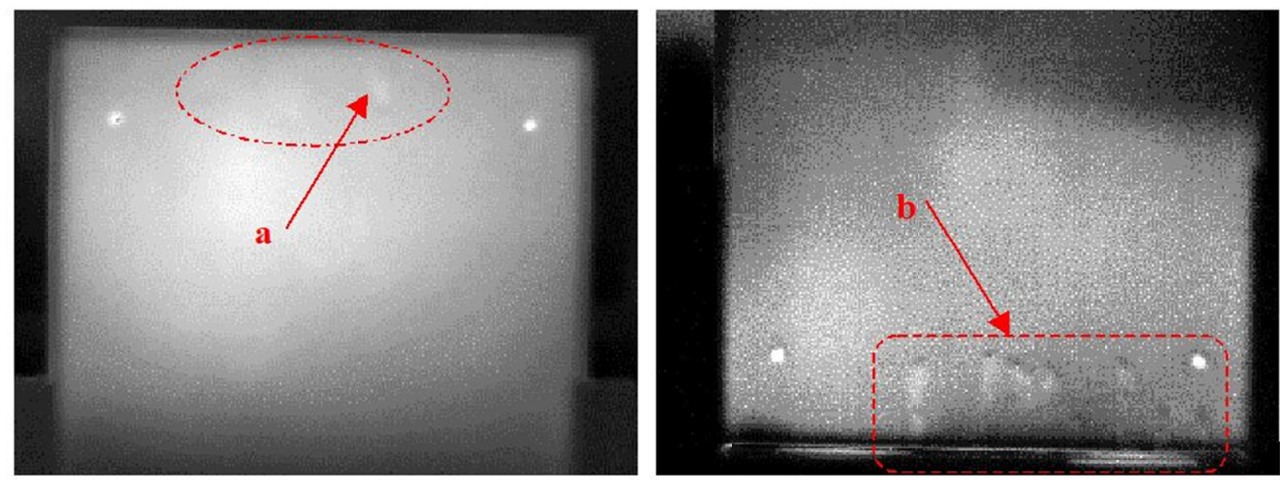

Figure 3. Thermographic image of the upper (left) and lower (right) parts of the specimen shown in figure 2

Based on the previous paragraph, we proceeded to test a sonic technique (Spanner, 1974; Dunegan \& Tetelman, 1987; Brigss, 1985; Pollock, 1998) that works by scanning, between 2 and $70 \mathrm{KHz}$, with continuous Lamb wave in emission-reception on the same side of the piece. This technique has the advantage that operating from one side of the radome is able to reveal discontinuities located on both sides of the radome. Moreover, due to the low operating frequency, it does not require any coupling means, so it is a dry contact technique; being the emitter and receiver probes provided with a Teflon sole that facilitates the displacement through the piece. Other advantages of the technique are: the ease of adjustment from appropriate test pieces and the fact that in the absence of contact of some of the probes with the piece, the signal obtained (becomes smaller) evolves in the opposite direction that when in the presence of a discontinuity (the signal increases in size), which avoids the detection of false positives (Ramirez et al., 1996). Operating from one side, this technique was able to detect all the discontinuities present in the specimen (upper, lower, and central bands) that the ultrasounds had revealed. Figure 4 shows the signals obtained in one of the discontinuities. On the right side of the image is represented the signal obtained in a good area, while on the left side you can see the signal when a discontinuity is present. 

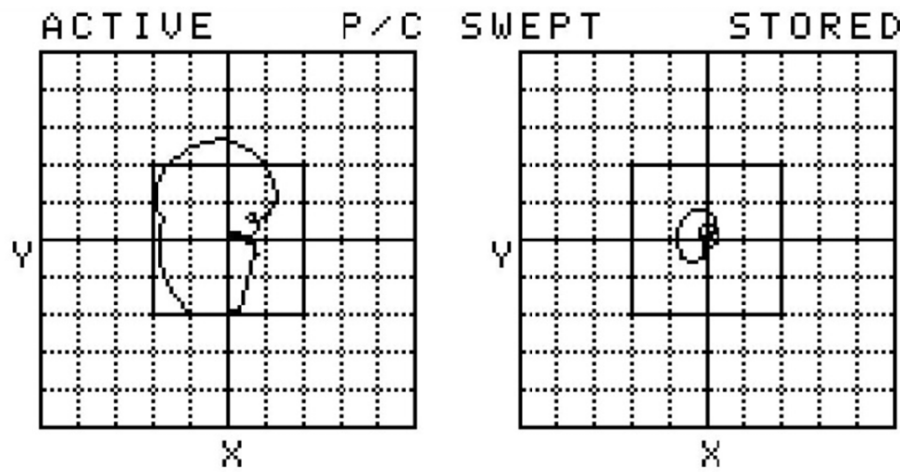

Figure 4. Signals obtained with a sonic technique for detecting discontimuities

Although it is not feasible for X-rays to detect flat discontinuities, it can be thought that when the discontinuity is volumetric, it can be revealed by X-ray. In this case the nucleus is so light and absorbs so little radiation compared to "skins" that the existence or not of a nucleus does not influence the radiographic image. Thus, cavities with a diameter of the order of $50 \%$ of the thickness of the core do not provide any indication. Thermography behaves somewhat better in the case of volumetric discontinuities in the core, but also the contrast obtained in this type of material is low.

\subsection{Test on Parts}

They were made mainly combining the visual, radiographic, thermographic and sonic (Lamb waves) methods, obtaining the results that are specified in the figures that will be shown later. The sonic method was used to detect flat discontinuities in the sandwich, since, although in principle, it does not provide images, it is the only one of those available that can detect them reliably. From the analysis of the results of the three remaining methods, it is clear that only some discontinuities are detected by all three methods; others by only two of them and some by only one. In general, volumetric discontinuities, such as cavities or resin pockets, or anomalies affecting the fiberglass fabric (breaks, splices, folds, etc.) are well seen visually and by radiography and occasionally by thermography. On the other hand, the discontinuities that affect the core of the material, for the reasons mentioned in the previous section, are only perceptible by thermography and, when the piece is not painted, visually (Craik \& Vernon, 1941; Von Helmholtz, 1963; Reynolds, 1996).

Also included is an image obtained by means of UVA (figure 5) that demonstrates how this band of the spectrum is especially useful for detecting certain types of inclusions and the irregular distribution of the resin on the surface observed (Rosenthal \& Trolinger, 1995; Steton \& Ferraro, 1993; Erf, 1974).

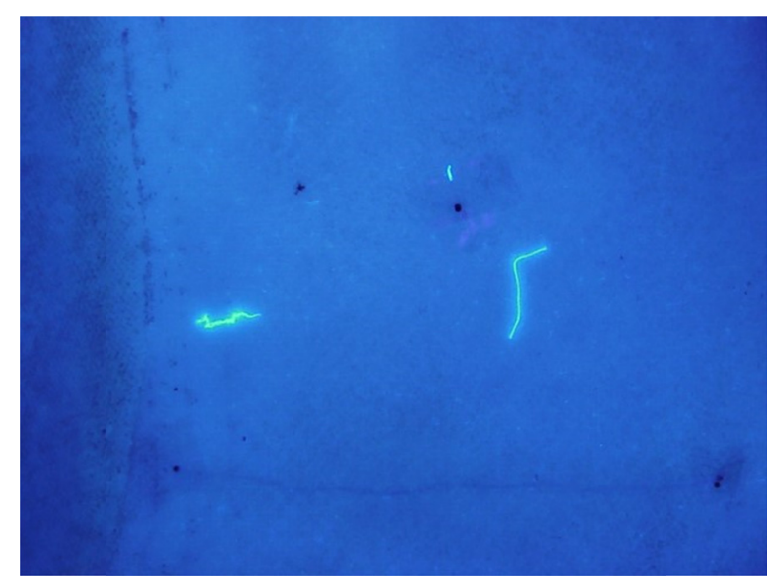

Figure 5. Image obtained by UVA. In light color, some inclusions are shown in the form of a filament

Figure 6a shows an X-ray (Bermúdez, 1963; Sproull, 1946) of an area where a break in the "skin" of the interior of the piece had been visually detected (see photograph in figure 6c). This breakage gives a clear indication (arrow a, figure 6a) between the two white circles. There is a vertical discontinuity (arrow b), probably due to a break in the fabric on the outside that is painted, since this is not visually observed on the inside.

The discontinuities indicated by arrows $\mathrm{a}$ and $\mathrm{b}$ did not provide indications when inspected by thermography. 
Arrows c indicate an area with irregularities in the resin distribution (probably additional resin has been added), whose shape coincides exactly with the indication shown in the thermographic image in filgure $6 \mathrm{~d}$.

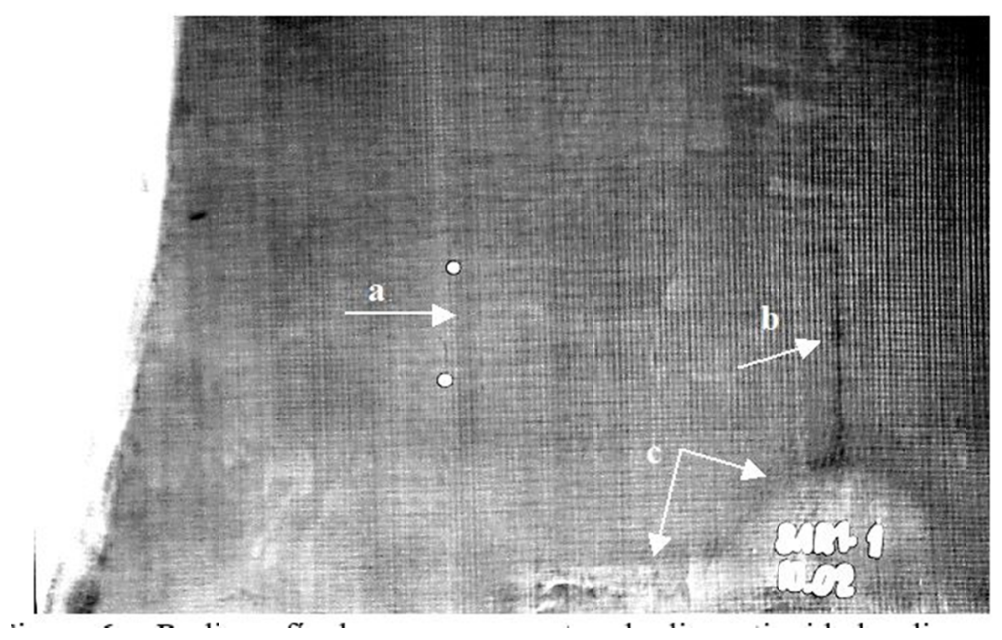

Figure 6a. X-ray of an area showing various discontinuities

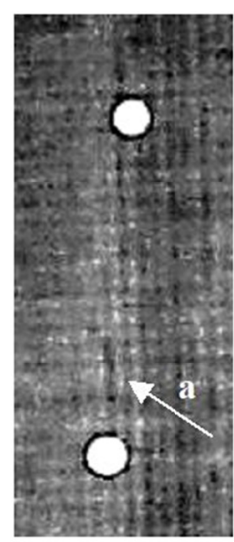

Figure 6b. Radiographic detail of discontinuity marked with the arrow a in figure $6 \mathrm{a}$

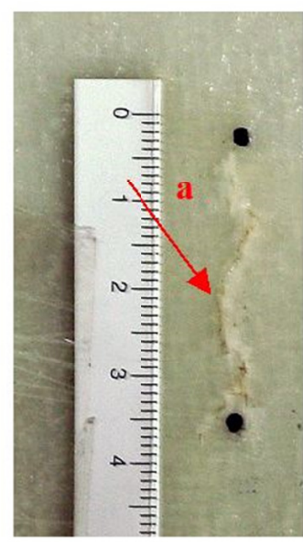

Figure 6c. Visual detail of the discontinuity marked with the arrow $\mathrm{b}$ in figure $6 \mathrm{a}$

In the thermography there is a vertical indication (arrow d) in the central area that runs along the longitudinal axis of the radome and has no relationship with the radiographic indication indicated by the arrow $\mathrm{b}$ in figure $6 \mathrm{a}$. Although the reason for the existence of this indication is unknown to us, it is clear that it is in the manufacturing process itself.

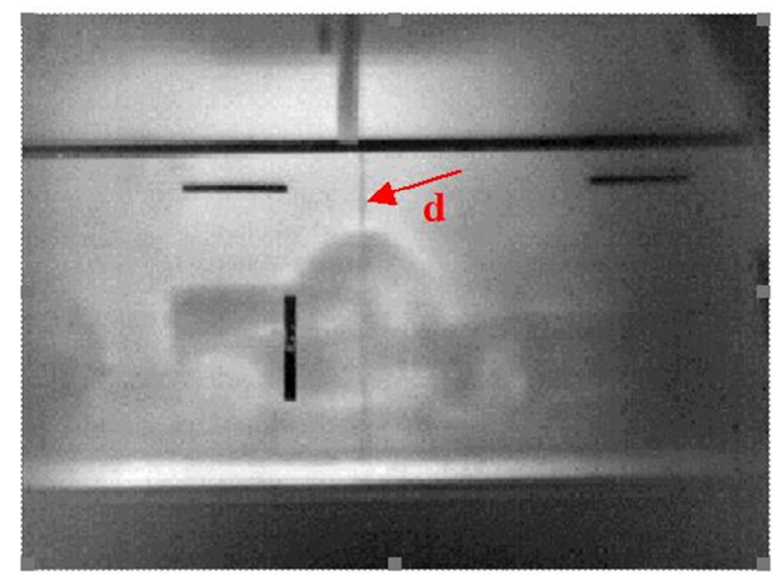

Figure $6 \mathrm{~d}$. Thermography of a zone partially coincident with the one shown in figure $6 \mathrm{a}$ 
In figure 7a you can see the photograph of an area, located in the agreement between the central sandwich and the side panel, where there are gaps due to lack of resin. The radiographic aspect of the discontinuity is indicated with the arrow a in figure $7 \mathrm{~b}$, where discontinuities can also be seen in the fabrics that form the union between the sandwich and the lateral panel (arrows b).

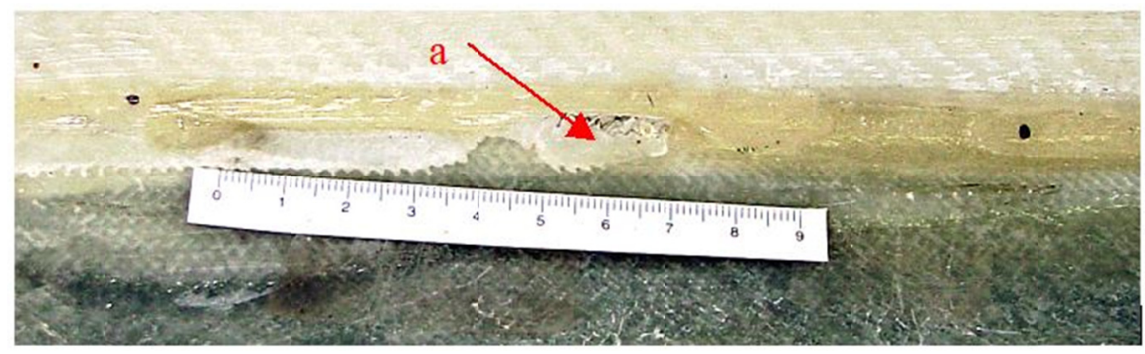

Figure 7a. Visible image of an area with holes due to lack of resin

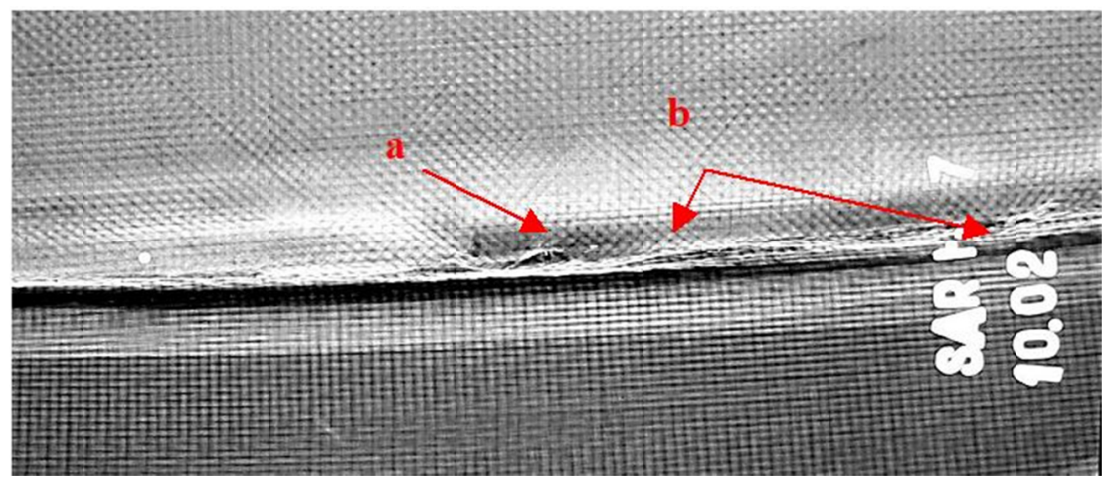

Figure 7b. X-ray of the area shown in figure $7 \mathrm{a}$

The thermography corresponding to this zone of the agreement is shown in figure $7 \mathrm{c}$, where the zone with holes appears as a narrow vertical band of light color.

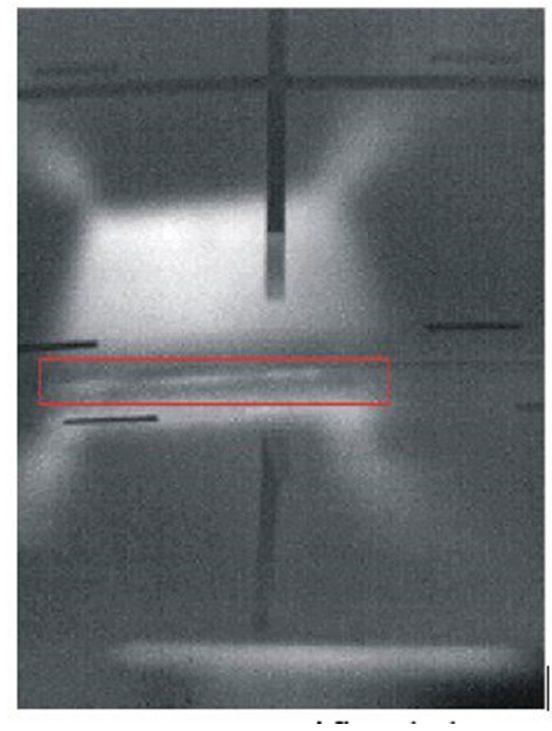

Figure 7c. Thermographic image of the area with holes in figure 7

Figures $8 \mathrm{a}$ and $8 \mathrm{~b}$ show radiographic images of the sandwich covering, with a certain overlap area, the whole width of the piece in one of its curved areas. In them, several discontinuities can be observed that affect the core, the skins and the agreement between the sandwich and the side panel. 


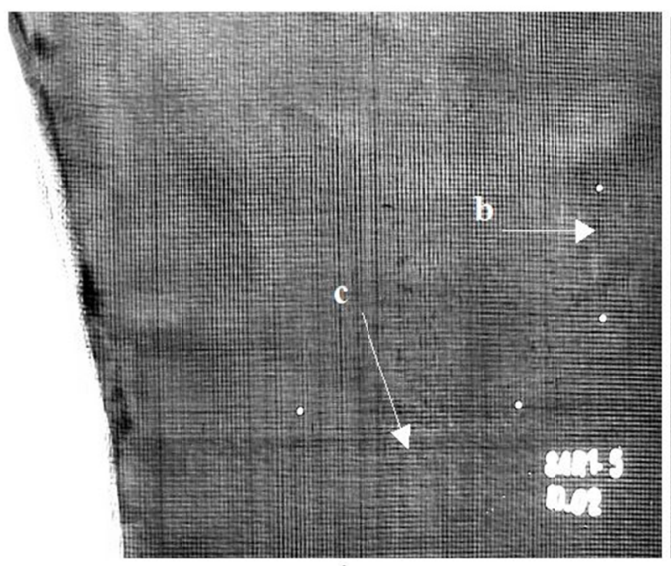

Figure 8a

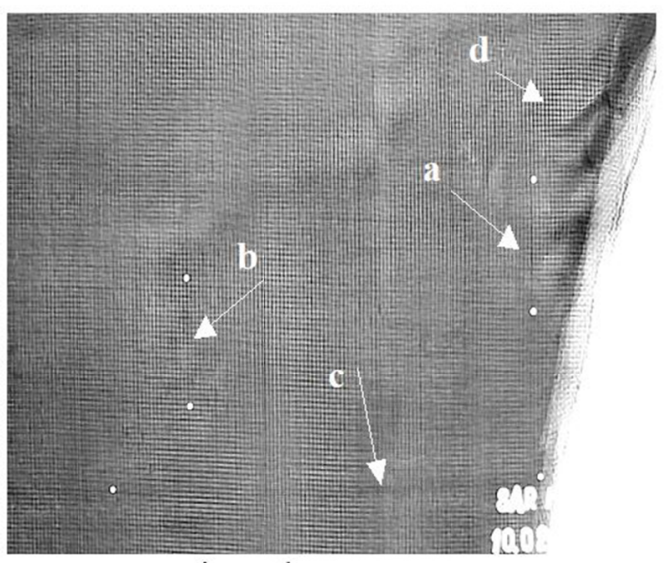

Figure $8 b$

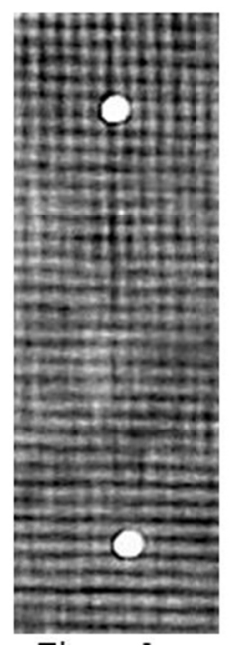

Figure 8c

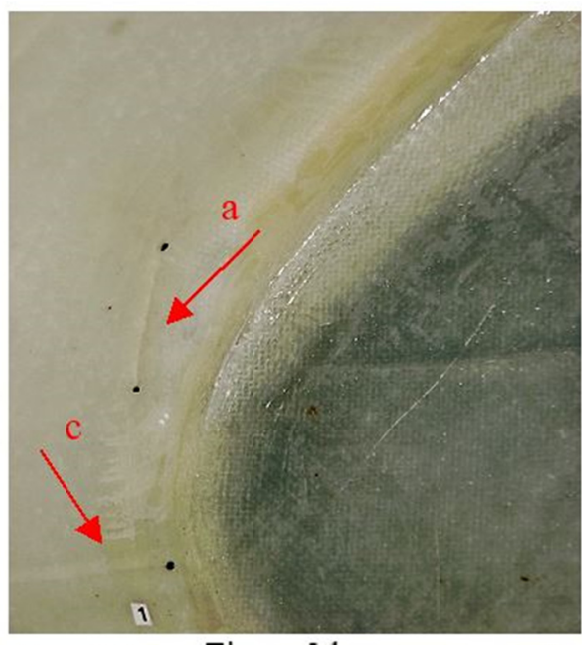

Figure 8d

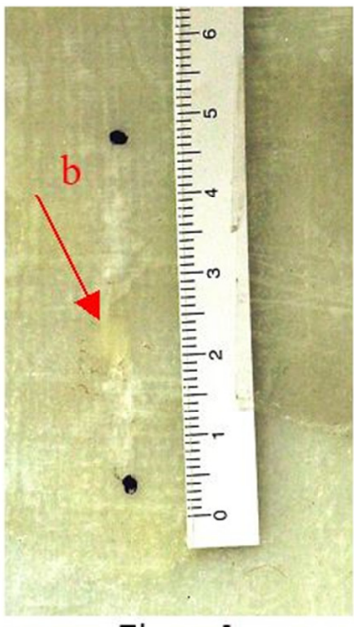

Figure 8e

Figure $8 \mathrm{~d}$ shows the visual aspect of a fiber break (arrow a) in the inner fabric of the piece. The corresponding radiographic indication is the one indicated by the arrow a in figure $8 \mathrm{~b}$, being presented in figure $8 \mathrm{c}$ a detail of the same one. However, the vertical line that appears in the photograph in figure 8e (arrow b), should be very superficial and affect only the outer layer of resin, since its radiographic indication, marked by arrows $b$ in figures $8 \mathrm{a}$ and $8 \mathrm{~b}$, is barely perceptible. The thermographic inspection of the area did not clearly reveal any of the two discontinuities.

Likewise, in figure 8d, part of a union joint practiced in the nucleus (arrow c) can also be seen, which gives rise to diffuse radiographic indications marked by arrow $\mathrm{c}$ in figures $8 \mathrm{a}$ and $8 \mathrm{~b}$. The indications due to the joint are clearly visible in the thermographic image in figure $8 \mathrm{f}$ (arrow c).

Both on the left side of figure $8 \mathrm{a}$ and on the right side of figure $8 \mathrm{~b}$, there are dark areas caused by cavities and areas with lack of resin, located in the agreement between the sandwich and the side panels. The indications marked with arrow $\mathrm{d}$ in figure $8 \mathrm{~b}$ coincide exactly with those seen in the thermographic image represented in figure 8f (arrow d). 


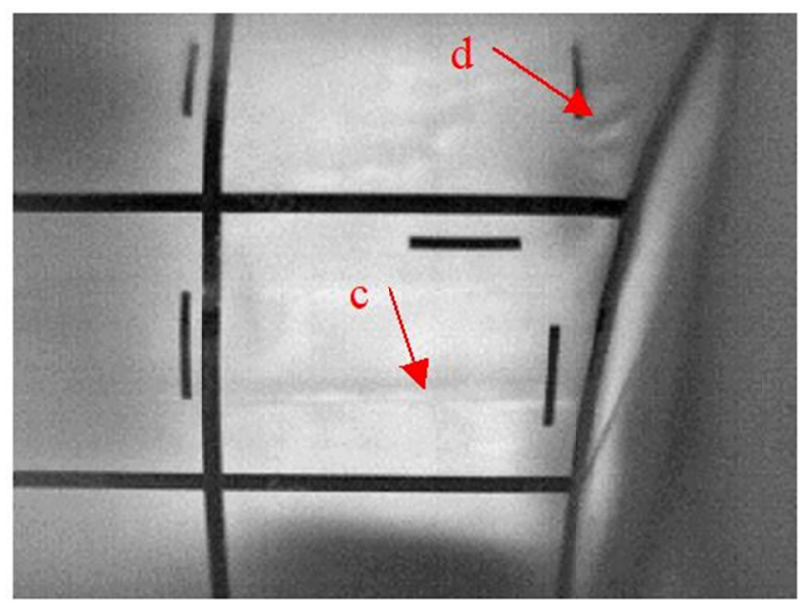

Figure $8 \mathrm{f}$. Thermography corresponding to the same area as the radiography in figure $8 \mathrm{~b}$

Figure 9a represents the radiographic image of an area where folds and broken tissue are detected (arrow a), in addition to a slightly curved vertical indication. These discontinuities must be on the outer side of the radome, where they cannot be observed by visual inspection, since the piece is painted on that side. Figure 9d, which corresponds to the thermography of this area, shows very remarkable concordance between the two methods, although the X-ray provides more information in this case (Halmshaw, 1966).

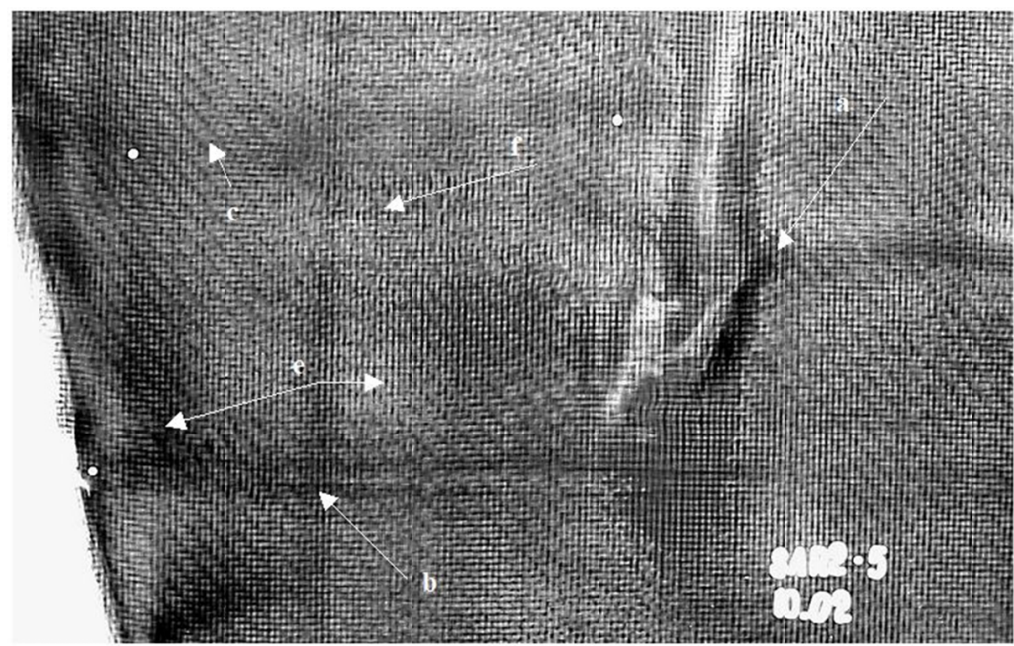

Figure 9a. X-ray showing tissue ruptures and other discontinuities

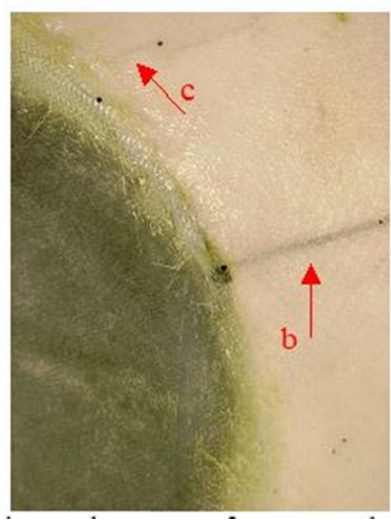

Figure 9b. Photo showing a seal (arrow b) and a break (arrow c) of the core

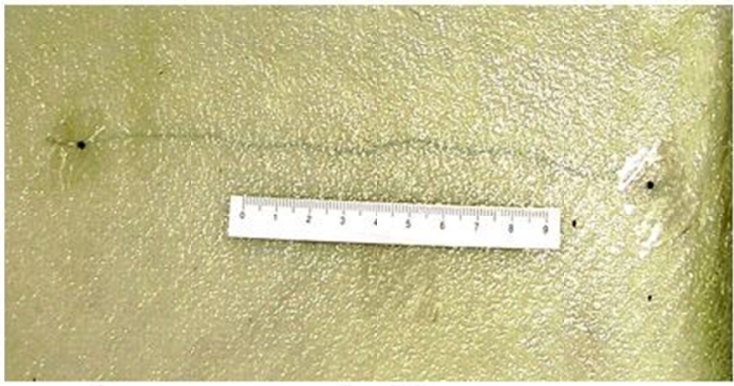

Figure 9c. Visual aspect of a core break 


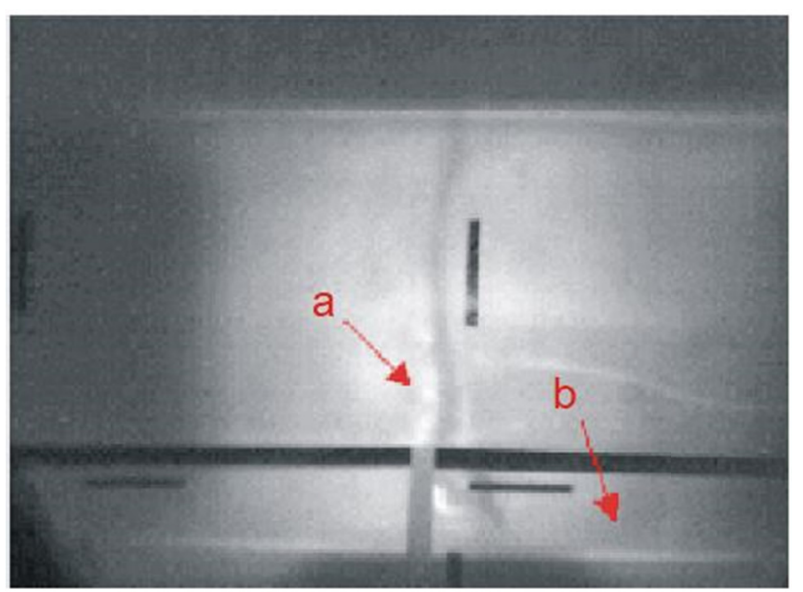

Figure $9 \mathrm{~d}$. Thermography of the area shown in figure $9 \mathrm{a}$

The arrows $b$ in the entire group of figures 9 point to a joint in the foam core. Figure $9 \mathrm{~b}$ shows what it looks like with the naked eye when the surface from which it is viewed is not painted, while figures $9 \mathrm{a}$ and $9 \mathrm{~d}, 9 \mathrm{e}$ compare the indications provided by the radiographic and thermographic methods, respectively.

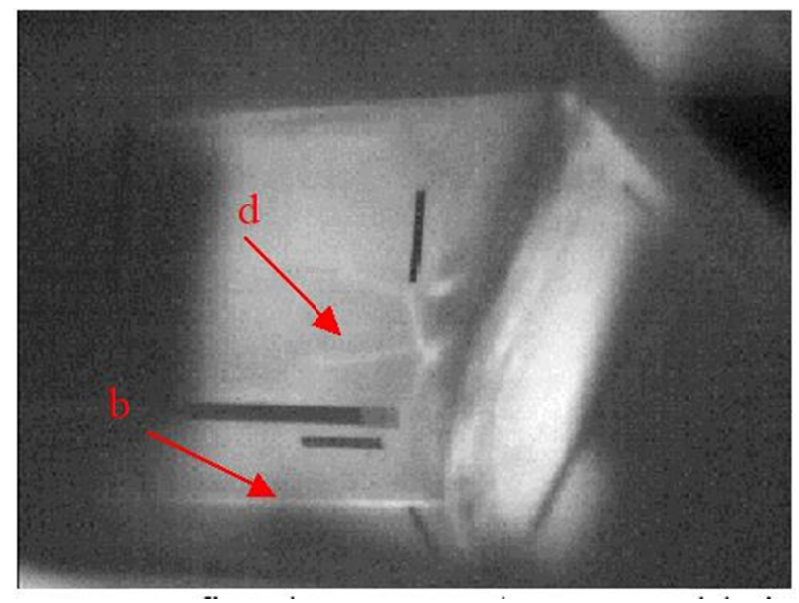

Figure 9e. Thermography showing a branched core ruptura

Core breaks, such as the one shown in Figure 9c, are not detectable radiographically. Thus, the break marked with the arrow $\mathrm{c}$ in figure $9 \mathrm{~b}$ does not give an indication in the radiographic picture of figure $9 \mathrm{a}$ (arrow c). On the other hand, these discontinuities provide a very clear indication when inspected by thermography, as can be seen in the place indicated by the arrow $d$ in figure 9e, where a branched break appears, which is not the same as that seen in figure 9c. The radiographic undetectability of the foam core breaks is due to the low density of the foam core compared to the material that composes the "skins". The case of the joints in the core is not comparable to that of the breaks, since other materials, such as fillers and adhesives, may exist in the joint, which facilitates radiographic detection ( Lendze et al., 2006; Kang et al., 2006).

The irregularities in the distribution of resin shown in figure 9a by arrows e and the deformations in the structure of the tissue (figure 9a, arrow f) are clearly observed in radiography, but not in thermography. 


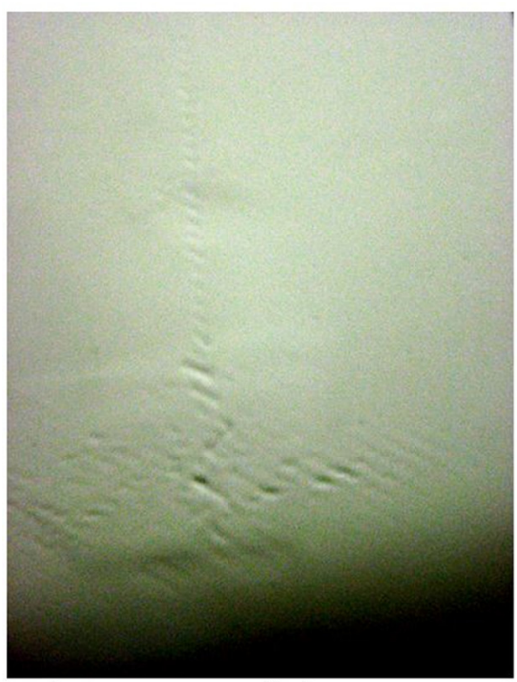

Figure 10a. Photograph of an area of the outer face of a radome

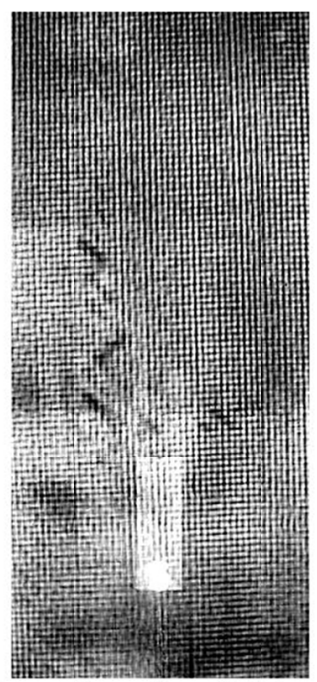

Figure 10b. X-ray of the area

shown in figure $10 \mathrm{a}$

The photograph in figure 10a corresponds to an area of the external face of a radome in which you can see quite deep dents and tracks, inclined at 45 degrees. The X-ray in figure 10b clearly shows the footprints due to the loss of thickness that they represent. The thermography (figure 10c), besides providing indications (not as clear as the $\mathrm{X}$-ray) of the prints, shows us an indication of dark color that is associated with the dented area; this indication is probably due to the fact that the fabric contains additional resin in that area.

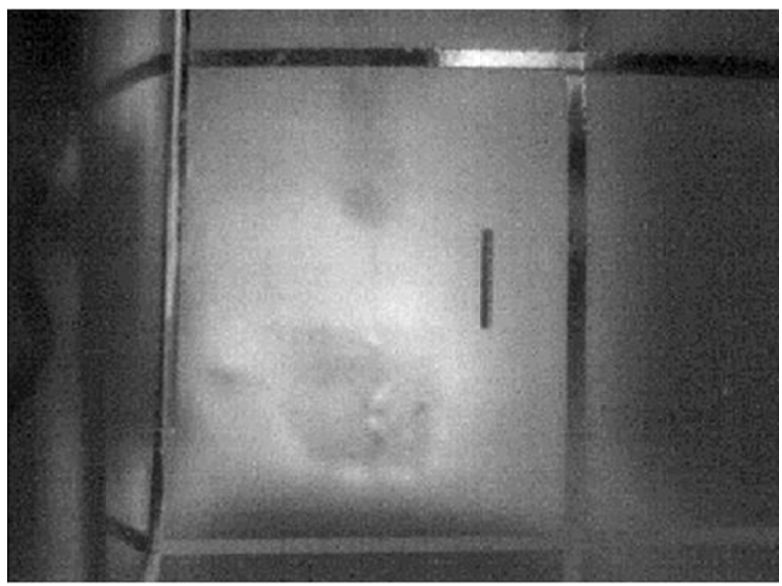

Figure 10c. Thermographic image corresponding to the area shown in figure 10a

The group of figures 11 illustrates a set of almost coincidental breaks in the fabric of both "skins" and in the core giving rise to a "through crack". In the photograph of figure 11a you can see a line (arrow a) in which the two layers of fabric are broken on the inner side, its radiographic indication is marked with the arrow a in figure $11 \mathrm{c}$. As it can be seen in figure $11 \mathrm{~b}$, the outer side of the piece also shows a very severe tear of the fabric. The appearance of this in radiography is indicated by the arrow $b$ in figure 11c. From the examination of the last figure, it can be deduced that the two ruptures are very close but their projection does not coincide and, given that in that area the nucleus is also broken, the set of the three discontinuities can be called "through crack".

When the fabric has a shortage of resin, its structure (weft and warp) is perfectly defined in the radiographic images, as shown in the area indicated by the arrow $\mathrm{c}$ in figure 11c. Likewise, the X-ray is also able to reveal if there are deformations of the tissue or deviations in its direction (arrow $\mathrm{d}$ in figure 11c). 


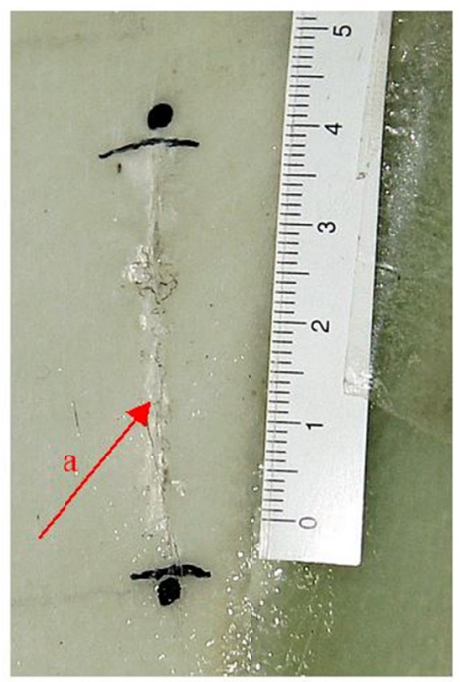

Figure 11a. Photograph showing a tear in the fabric on the inside

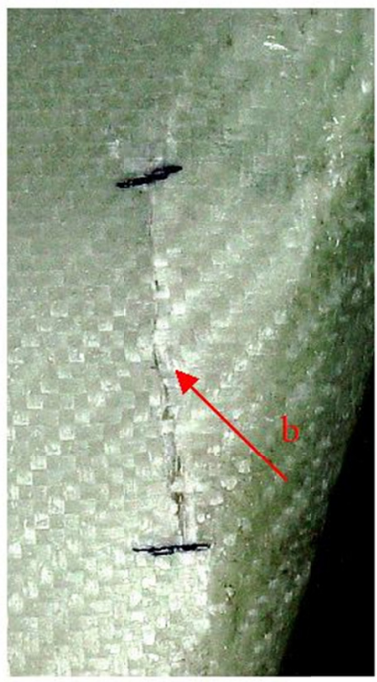

Figure 11b. Image of the exterior face showing a very severe break

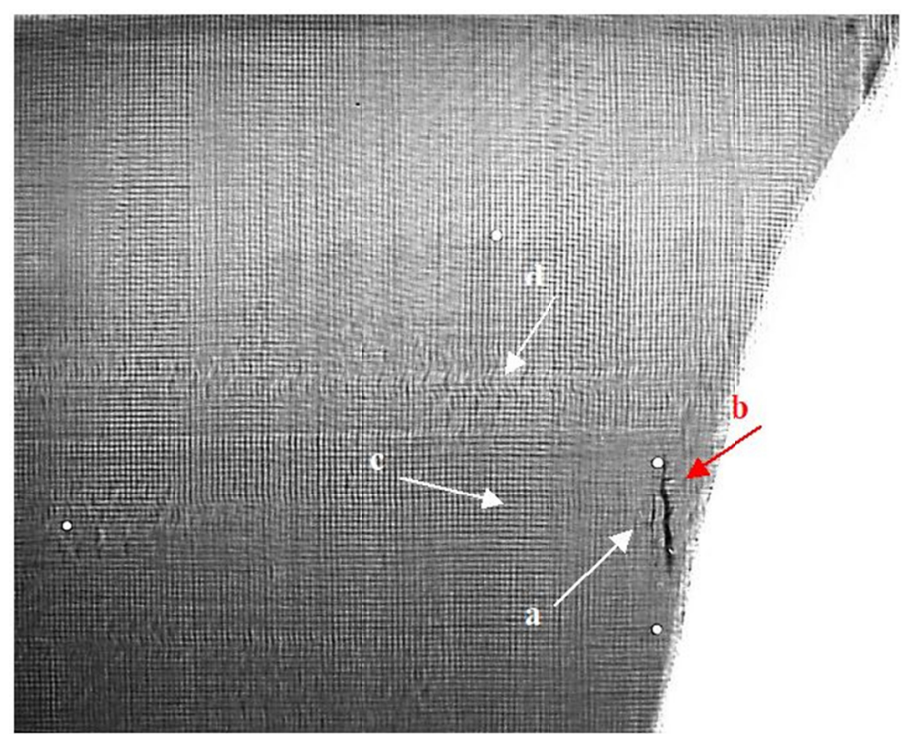

Figure 11c. X-ray showing the breaks in figures 11a and 11b, together with other discontinuities

In the photograph shown in figure 12, three discontinuities can be seen, indicated by arrows a and $b$. Of these, the one marked with arrow a is a break in the fabric that gives a clear indication in $\mathrm{X}$-ray, but the two lines marked with arrows b are not detected by any method, except visual, as long as the surface is not painted. In fact, what it seems, and is corroborated by radiographic examinations of the area, is that these visual indications are not due to breaks, but rather are caused by the existence of areas with a shortage of resin. The area with resin deficit extends around the linear visual indication in a much larger area than the same, and may already exist, or originate during the life in service, delaminations in the "skins" or detachments in the union "skin"-core. Likewise, it is possible that in the place where the linear indication is found, a breakage of the fibers of the fabric is originated when the piece is submitted to efforts. 


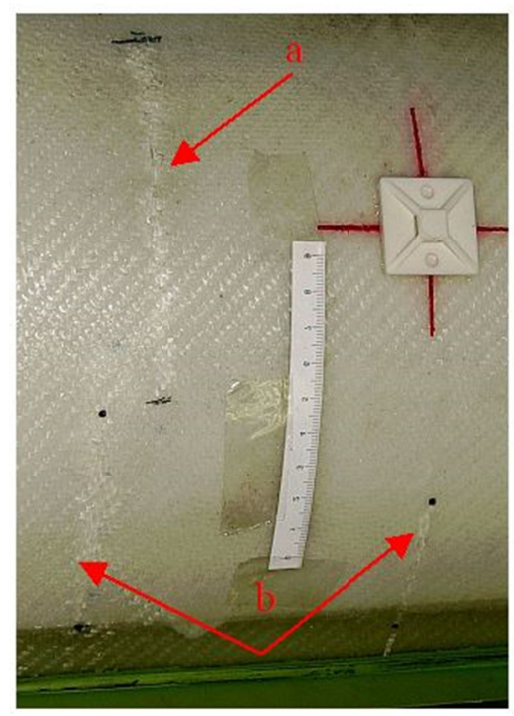

Figure 12. Visible image of an area in the outer curved part of a radome

\section{Conclusion}

Two kinds of conclusions are drawn from the results of the tests carried out. The first refers to the usefulness of the tests themselves in relation to the purpose of the inspection, which in this or any other case is simply to determine whether the object is suitable for the purpose for which it was conceived; that is, whether its "quality" is sufficient. The latter is intended to show the degree of coverage that the concurrence of several non-destructive tests provides to the knowledge of the discontinuities affecting the object.

\subsection{Recommendations}

Regarding the determination of its usefulness, we will limit ourselves to a couple of considerations, since it is not the purpose of this paper to explain whether the radome is useful or should be rejected. Firstly, it is necessary to underline the impropriety of undertaking tests without the project engineering having previously established sufficient criteria to determine what is to be sought and what technological meaning is to be found. Secondly, since this is not the case, the multiplication of tests could lead to more confusion than useful knowledge. Certainly the absence of indications, if given, "could" be interpreted in a good sense as an indication of the absence of discontinuities. But this is not the case, and there are indications that can be interpreted as discontinuities, identifiable at least morphologically, that cannot be given "a priori" as irrelevant because of their magnitude and amount. In the absence of specifications the only sensible thing to do is to quarantine the quality of the object. That is: its good behavior in service according to the purpose of use with which it was made.

The other conclusions, which are those that justify this work, can be summarized in the evidence shown in it about how the "concurrent" methods not only reinforce confidence in the real existence of the discontinuities highlighted by them, but also, and mainly, how they help each other to establish their nature and morphology.

As regards the performance of the methods as "complementary", it seems clear that it represents an extension of the coverage of the knowledge regarding the existence of discontinuities, and a valuable contribution to the global judgement on the quality of the object, which engineering should value.

Bearing in mind the experience obtained and in accordance with the principle of good practice of reducing to the essential minimum the tests to be applied in the inspection of an object, it seems plausible that in the future it will be sufficient, for similar pieces that are not painted on any of their faces, with the direct and translucent visual inspection made before painting them, and the sonic inspection (Lamb waves) to detect delaminations and detachments. And only at specific points to confirm or elucidate the existence of discontinuities found by visual inspection, the radiography. If the part is painted on one or both sides, more methods must be used, with visual and radiographic inspection being necessary when the part has one painted side, and even thermography if breaks in the core are to be detected in a part that is painted on both sides. In all cases the inspection with the sonic technique will be necessary to reveal flat discontinuities. But this conjecture, however well founded it may seem, remains to be confirmed by technology. 


\subsection{Limitations}

In the case of visual inspection, the method provides immediate indications that often do not require elaborate interpretation. However, one should not be tempted to believe that 'what you see' is 'how you look'. In many cases, what is seen must be elaborated according to the materialographic aspects of the problem and even of the observation technique itself, such as the color of the light used, whether or not it is polarized, incidence of illumination, etc.

Radiographic inspection of this type of material does not present any difficulty. These materials are not very absorbent and require lower energies for inspection. If the thickness to be examined is small, the problem may be its excessive transparency that will force to have X-ray tubes with very low inherent filtration and even to dispense with the film cover, which will force to work under safety light. However, although it does not pose serious radiographic problems, the defectology of the composite material is usually not very conducive to radiographic inspection, since it consists of laminar-type discontinuities (delaminations) arranged parallel to the image and whose radiographic detectability is extremely poor. Another issue is the cracks or pores that could be present in the inspected piece, which do not present a problem to be evidenced, however this type of discontinuities are less frequent than the delaminations.

Manual testing by ultrasound requires highly qualified personnel. The large number of critical decisions to be made, together with the poor documentation of results, reduces the reliability of the tests, pushing this problem to the development of automated procedures. Small, irregular, rough or thin material samples are difficult to inspect. Heterogeneities very close to the surface are difficult to detect. Calibration of the test system and determination of certain characteristics of the defects to be inspected requires the use of standard or reference samples.

Defect detection techniques using Lamb waves (sonic techniques) allow continuous monitoring of the state of the structure and allow the integration of detection systems in critical areas of the part that require constant maintenance. These waves are dispersive, varying their speed of propagation according to the frequency. The efficiency of the transducer can be affected when the elements that compose it are close to the edge of the plate, and the latter can act in a reactive manner by interfering with the frequency band of the nodes. For the study of the edges, finite element analysis techniques are proposed.

The inspection using ultraviolet light does not detect too deep defects, and requires an electric power source. The roughness of the surface under study can affect the sensitivity of the test.

The methods of infrared thermography pulsed by reflection (infrared camera in front of the part as well as the heat source) and by transmission (infrared camera behind the part) present good results for small thicknesses, however, it is necessary a good adjustment on a test specimen with defects of different sizes and at different depths to adjust well this technique. It is very important the adjustments of the heat power provided by the focus and the times of incidence of the heat in the part since the processes of heat transfer could result negative in the visualization of the possible defects in the part.

\section{Acknowledgements}

The authors wish to thank the Instituto Nacional de Técnica Aeroespacial (INTA), especially the Central Remote Sensing and Non-Destructive Testing Laboratories.

\section{References}

ASM International Handbook Committee. (1989). Engineered Materials Handbook, vol. 1 Composites.

Baker, A. A., Jones, R., \& Callinan, R. J. (1985). Damage tolerance od graphite/epoxy composites. Composite Structures, 4, 15-44. https://doi.org/10.1016/0263-8223(85)90018-2

Balageas, D. (2005). Métodos innovadores de inspección de estructuras de materiales compuestos. Materiales Compuestos, 5, ed. V Amigó et al., Editorial de la Universidad Politécnica de Valencia, pp. 1065-1080.

Bales, M. J., \& Bishop, C. C. (1994). Pulsed Infrared Imaging: a New NDT Methodology of Aboveground Storage Tnaks. Bales Scientific, Inc., 1620. Tice Valley Blvd., Walnut Creek, CA 94595. Materials Evaluation.

Barbero, E. J. (1999). Introduce to Composite Materials Design. Taylord \& Francis, Inc.

Bermúdez de Castro, J. (1963). Los rayos X y sus aplicaciones industriales. Ed. Montecorvo. Madrid.

Bishop, S. M. (1985). The mechanical performance and impact behavior of carbon fibre reinforced PEEK. Composite Structures, 3, pp. 295-318. https://doi.org/10.1016/0263-8223(85)90059-5 
Brigss, A. (1985). An introduction to scanning acoustic microscopy. Oxford University Press. Royal Microscopical Society.

Cielo, P., Maldague, X., Déon, A. A., \& Lewak, R. (1987). Thermography Nondestructive Evaluations of Industrail Materials ans Structures. Materials Evaluation/45/April.

Clauser, H. R. (1952). Practical Radiography for Industry. Reynolds Publising Co. New York.

Craik, K. J. W., \& Vernon, M. D. (1941). Darkness Adaptation. Br. J. Phych 33.62. https://doi.org/10.1111/j.2044-8295.1941.tb01010.x

David, K., \& Hsu D. J. (2006). Nondestructive testing using air.bone ultrasound. Ultrasonics, 44, e1019-e1024. https://doi.org/10.1016/j.ultras.2006.05.091

David, k., Hsu, D. J., Barnard, J. J., \& Daniel, L. (2004). Applicatuion of air-coupled ultrasound in NDE of composite space atructures. Review of Quantitative Nondestructive Evaluation, 23.

De Smet, M. A. (1985). Holographic NonDestructive Testing for Composite Materials Used in Aerospace. SPIE, 599. Optics and Engineering Measurement. Cannes. https://doi.org/10.1117/12.952352

Dunegan, H. L., \& Tetelman, A. S. (1987). Acoustic Emission. Research and Development, 22(5), pp. 20-24.

ERF, R. K. (1974). Holographic Nondestructive Testing. United Aircraft Research laboratory, East Hartford, Connecticut. Academic Press.

Globe, D. T. (1979). The optical fibers as a transmisión Medium. Rep. Prog. Phys, 42(11).

Gray, S., Ganchev, S., Qaddoumi, N., Beauregard, G., \& Radford, D. (1995). Porosity level estimation in polymerer composites using microwaves. Applied Microwave Nondestructive Testing laboratory, Electrical Engineering Department, Colorado State University, Ft. Collins. Material Evaluation, pp. 404-408.

Halmshaw, R. (1966). Physic of Industrial Radiography. Ed. Heywood Books. London.

Hasiotis, T., Badoggiannis, E., \& Tsouvalis, N. G. (2007). Application of Ultrasonic C-Scan Techniques for Tracing Defects in Laminated Composite Materials. 4th Conference International on NDT.

Heru, S. B., Komotori, J., Shimizu, M., \& Miyano, Y. (1997). Effects of the fiber content on the longitudinal tensile fracture behavior of uni-directional carbon/epoxy composites. Journal of Materials Processing Technology, 67, pp. 89-93. https://doi.org/10.1016/S0924-0136(96)02824-5

Huang, Y. D., Liu, L., Zhang, Z. Q., \& Wan, Y. (1998). On-line monitoring of resin content for film impregnation process. Composites Science and Technology, 58, pp. 1531-1534. https://doi.org/10.1016/S0266-3538(97)00185-1

ImieliĚska, K., Castaings, M., Wojtyra, R., Haras, J., Le Clezio, E., \& Hosten, B. (2004). Air-coupled ultrasonic $\mathrm{C}$-scan technique in impact response testing of carbon fibre and hybrid: glass, carbon and Kevlar/epoxy composites. Journal of Materials Processing Technology, 157-158, pp. 513-522. https://doi.org/10.1016/j.jmatprotec.2004.07.143

Kang, K., Choi, M., Kim, K., Cha, Y., Kang Y., Hong, D., \& Yang S. (2006). Inspection of impactdamage in honeycomb composite plate by spi, ultrasonic testing, and thermography. 12th A-PCNDT-Asia Pacific Conference on NDT.

Kapranos, P., \& Priestner, R. (1987). NDE of difusión bonds. Metals and Materials, pp. 194-198.

Krapez, J. C., Taillade, F., \& Balageas, D. (2003). Untrasound-lock in thermography NDE of composite plates with low power actuators. Experimental investigation of the influence of Lamb wave frequency. QUIRT Journal, 2(2), pp. 191-206. https://doi.org/10.3166/qirt.2.191-206

Lawson, W. D., \& Sabey, J. W. (1970). Infrared Thecniques, Research Thecniques in Nondestructive Testing. Ed. R. S. Sharpe, Academic Press, N. Y. cap. 14. pp. 443-479.

Lendze, T., Wojtyra, R., Guillamumat, L., Biateau, C., \& Imieli'nska, K. (2006). Low velocity impact damage in glass/polyester composite sándwich panels. Advances in Materials Science, 6(1), 9.

Maldague, X. (2001). Theory and practice of infrared technology for nondestructive testing. Wiley Series in Microwave and Optical Engimeering. John Wiley \& Sons.

Mitrevski, T., Marshall, I. H., \& Thomson, R. (2006). The influence of impactor shape on the damage to composite laminates. Composite Structures, 76, 116-122. https://doi.org/10.1016/j.compstruct.2006.06.017 
Miyano, Y., McMurray, M. K., Kitade, N., Nakada, M., \& Mohri, M. (1994). Role of matrix resino $n$ the flexure static behavior of unidirectional pitch-based carbon fiber laminates. Advanced Composite Materials, 4(2), pp. 87-99. https://doi.org/10.1163/156855194X00222

Mouritz, A. P., Townsend, C., \& Shah Khan, M. Z. (2000). Nondestructive detection of fatigue damage in thick composites by pulse-echo ultrasonics. Composites Science and Technology, 60, pp. 23-32. https://doi.org/10.1016/S0266-3538(99)00094-9

Ochelski, S. (2004). Experimental methods in construction composites mechanics. WNT, Warszawa (in Polish).

Padmanabhan, K., \& Kishore E. (1995). Failure behaviour of carbon fibre/epoxy composites in pìn-ended buckling and vending test. Composites, 26(3), pp. 201-206. https://doi.org/10.1016/0010-4361(95)91383-G

Pollock, A. A. (1998). Acoustic Emission Inspection. Metal Handbook. Vol. 17. Nondestructive and Quality Control, pp. 278-294.

Potel, C., Chotard, T., Belleval, J. F., \& Benzeggagh, M. (1998). Characterization of composite material by ultrasonic methods. Composites Part B, pp. 159-169. https://doi.org/10.1016/S1359-8368(97)00006-1

Rámirez López, Fc., Del Ojo, G., Fernández Soler, M. A., Valdecantos, C., Alonso, A., \& De los Ríos, J. M. (1996). Métodos de Ensayos No Destructivos, Instituto de Técnica Aeroespacial (INTA).

Ramírez, F., Delojo, G., Fernández, M. A., Valdecantos, C., Alonso, A., \& De los Ríos, J. M. (1996). Métodos de Ensayos No Destructivos. Instituto Nacional de Técnica Aeroespacial "Esteban Terradas". Tomos I y II. Madrid. España.

Reynolds, V. N. (1996). Optical and Infrared Methods, (part. 8 of Capabilities and Limitations of NDT). Ed. P. D. Hanstead). The Br. Inst. of NDT. Northampton.

Rosenthal, D. M., \& Trolinger, J. D. (1995). Holographic Nondestructive Testing. Metro-Laser, 18006 Skypark Circle. Suite 108, Irvine. Materials Evaluation.

Sanglier, G., López, E. J., Cesteros, S., \& González, R. A. (2020). The Search for 'Defects' by Non-invasive Techniques: Developmente and Application of Pulsed-Transmissive and Refective Thermography in Fiberglass Material. Contemporary Engineering Sciences. https://doi.org/10.12988/ces2020.91245

Sanglier, G., Del Ojo, G., De Miguel, J., \& Peñaranda, J. A. (2003). Estudio mediante Ensayos No Destructivos dela cubierta ("Radomo") de un sistema experimental de radar de apertura sintética. $10^{\circ}$ Congreso nacional de E.N.D. Asociación Española de Ensayos No Destructivos. Cartagena, España.

Scarponi, C., \& Briotti, G. (2000). Ultrasonic technique for the evaluation of delamination on CFRP, GFRP, KFRP composite materials. Composites: Part B, 31, pp. 237-243. https://doi.org/10.1016/S1359-8368(99)00076-1

Silk, M. G. (1982). Defect detection and sizing in metals using ultrasound. International Metal Rev., 1, pp. 28-50. https://doi.org/10.1179/imr.1982.27.1.28

Spanner J. C. (1974). Acoustic Emission Techniques and Aplication. ASNT. Columbus (Ohio) 43221.

Sproull, W. T. (1946). X Rays in Practice. Ed. Mc Graw Hill. New York. https://doi.org/10.1097/00010694-194608000-00018

Stetson, K. A., \& Ferraro, P. (1993). Cooperative Research and Development Programo on Holographic Nondestructive Testing. Task II Report.

Von Helmholtz, H. (1963). Handbook of Physiological Optics. Reimpresión por Stanthall. Dover.

Wan, H., Ning, F., Hu, Y., Fernando, PKSC, \& Pei, Z. J. (2016). Surface grinding of carbon fiber-reinforced plastic composites using rotatory ultrasonic machining: Effects of tool variables. Advanced in Mechanical Engineering, 8(9), 1-14. https://doi.org/10.1177/1687814016670284

\section{Copyrights}

Copyright for this article is retained by the author(s), with first publication rights granted to the journal.

This is an open-access article distributed under the terms and conditions of the Creative Commons Attribution license (http://creativecommons.org/licenses/by/4.0/). 